\title{
XXVIII. Note on the spark-discharge
}

\section{Siegfr Guggenheimer Ph.D.}

To cite this article: Siegfr Guggenheimer Ph.D. (1901) XXVIII. Note on the spark-discharge , Philosophical Magazine Series 6, 2:9, 311-317, DOI: 10.1080/14786440109462693

To link to this article: http://dx.doi.org/10.1080/14786440109462693

$$
\text { 册 Published online: } 08 \text { Jun } 2010 .
$$

6 Submit your article to this journal $\pi$

Џ Article views: 2

Q View related articles $₫$ 
Dr. S. Guggenheimer on the Spark-discharge.

But when the galvanometer-arm is closed during the next $60^{\circ}$, the current through the galvanometer is in the opposite direction, for it is represented by the area EFG; thus $\mathrm{R}_{d}$ would appear less than $\mathrm{R}_{c}$.

These experiments were made in the New Physical Laboratory of the Owens College, Manchester: where, in order to complete the research, I hope to be able to investigate the relations between the magnitude and phase of the "bismuth E.M.F." and the field-strength; also to investigate the whole effect at the temperature of liquid air.

XXVIII. Note on the Spark-discharge.
$B y$ SIEgrr. GUGgenheimer, Ph.D.*

TWHE interest in the phenomena accompanying the sparkdischarge in gases has been revived recently by a discussion between Mr. Swyngedauw $\uparrow$ and Prof. Warburg $\ddagger$. The complete discordance between the opinions of these authors led me to undertake the experiments described below with the view eventually to decide the question at issue. I may at once say that the result of my experiments and theoretical considerations is to confirm the views of Prof. Warburg.

1. The fact that the spark-potential is independent of the nature of the radiation employed to shorten the time of retardation (Warburg's Verzögerung) made it seem probable that this potential depends upon the momentary state, i.e. upon the degree of ionization of the gas. Therefore it was to be expected that the "Verzögerung" would also be destroyed, or at least shortened, if, instead of using direct radiation, we introduce a sufficient number of ions in the space containing the sparking system. The experiments confirmed this expectation.

2. In the sides of a brass tube $20 \mathrm{~cm}$. long and $3 \mathrm{~cm}$. interior diameter were fitted two ebonite plugs facing one inother. Through each of these plugs passed a brass wire terminated inside the tube by a brass ball of $7 \mathrm{~mm}$. diameter.

* Communicated by Prof. J. J. Thomson, F.R.S.

+ R. Swyngedauw, Journ. de Phys. ix. p.. 488 (1900) ; Bichat \& Swyngedauw, Rapports of the Paris Congress, iii. p. 164 (1900).

f E. Warburg, Verhandlungen der Deutsch. Phys. Gesell. ii. p. 212 (1900). 
312 Dr. S. Guggenheimer on the Spark-discharge.

Opposite these electrodes was an aluminium window over which a hrass cover could be placed. One end of the tube was connectel to a U-tube filled with calcium chloride and thence to a wash-bottle containing concentrated sulphuric acid. The other end of the tube was connected by means of a glass tube (from $8 \mathrm{~mm}$. to $2 \mathrm{~cm}$. diameter and $10 \mathrm{~cm}$. length) to a second brass tube of $20 \mathrm{~cm}$. length, and of the same diameter

Fig. 1.

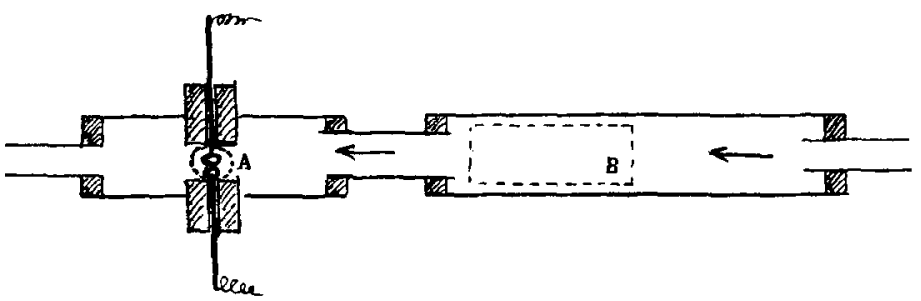

as the first one. This second tube was connected at the other end by means of a U-tube containing calcium chloride to a blowpipe. In the side of this brass tube was an opening $8 \mathrm{~cm}$. long and $2 \mathrm{~cm}$. broad, which was closed by thin aluminium-foil.

One part of the electric circuit comprised the one pole of a Wimshurst machine, the inner coating of a leyden-jar, one of the spherical electrodes, and the indicating portion of a Braun electrometer; the other part of the circuit consisted of the other pole of the Wimshurst, the outer coating of the leyden-jar, the other sphere, and the cage of the electrometer, and was generally put to earth.

The observations were carried out in the following order:(1) The discharge-potential was measured without exposing the sparking system to radiation, and without introducing ions into the tube A. Then (2) from an X.ray bulb placed near the aluminium window of the tube $B$, strong $X$-rays entered $B$, and the ions thus produced were driven by a strong current of air into the tube $A$, and the potential was measured whilst this operation went on. (3) A third measurement was then made whilst X-rays fell directly through the aluminium window in A upon the electrodes. The current of air was also blown through the apparatus during the operations 1 and 3 . Sheets of lead protected A when B was exposed to radiation.

I give below the results of two particularly striking series of experiments. 
Dr. S. Guggenheimer on the Spark-discharge.

Distance of the spheres (roughly) $=1 \mathrm{~mm}$. Potential V in Volts.

\begin{tabular}{|c|c|c|c|}
\hline & $\mathrm{V}$. & v. & $\nabla$. \\
\hline Without radiation & 4500 & 5500 & 5500 \\
\hline Radiation in $\mathbf{B} \ldots . .$. & 3500 & 3500 & 3500 \\
\hline A ..... & 3500 & 3400 & 3200 \\
\hline \multicolumn{4}{|c|}{ Distance of spheres (roughly) $=2 \cdot 1 \mathrm{~mm}$. } \\
\hline Without radiation & 7500 & 8000 & 8000 \\
\hline Radiation in $\mathbf{B}$. & 6000 & 5500 & 5800 \\
\hline $\mathbf{A} \ldots \ldots$ & 6000 & 6100 & 5900 \\
\hline
\end{tabular}

I am compelled to observe that the observations do not always give such concordant results for the cases of the radiation in $\mathrm{B}$ and $\mathrm{A}$ as shown in the above tables. If the electrodes are not freshly polished, and if the radiation in B is not strong enough (so that fewer ions are produced), then the results obtained are of the type shown by the following table :-

Distance of the spheres $=2 \cdot 1 \mathrm{~mm}$.

\begin{tabular}{|c|c|c|c|}
\hline & V. & v. & V. \\
\hline Without radiation & 8500 & 8000 & 8500 \\
\hline Radiation in B........... & 7000 & 6800 & 7000 \\
\hline$" \quad \mathbf{A} \ldots$ & 6000 & 6100 & 6000 \\
\hline
\end{tabular}

Here one sees the discharge with radiation in B taking place at potentials lying between the potentials obtained for discharges without introduction of ions or without direct radiations, and the potentials measured in exposing the sparking system to direct radiation. But the potentials necessary to produce the discharge were always about 1000 to 1500 volts lower than those measured without employing any means to destroy the retardation.

3. It might be permissible to insert here a few words with a view to a theoretical explanation of these results. There are, in my opinion, mainly two points to be considered which. 
314 Dr. S. Guggenheimer on the Spark-discharge.

so far as I am aware, have not yet been taken into consideration in the various attempts that have been made to explain the phenomena of retardation and of the spark-discharge in general. These two points are-(1) The fact discovered by Geitel* and by C. T. R. Wilson $\dagger$, that the air always contains ions, and that there is a continuous production of ions connected naturally with the re-combination of these ions. (2) The principle first established by Prof. J. J. Thomson $\ddagger$, and also brought forward and strengthened by experiments executed in the Cavendish Laboratory by Prof. Townsend $\xi$, viz., the principle of the production of new ions by the collisions of negatively charged corpuscles moving under the influence of strong electromotive forces with the molecules of the gas.

A careful comparison of the resuits of experiments undertaken from different standpoints, shows that the electromotive force per $\mathrm{cm}$. which is required to give to the negative ions a velocity such that they can produce new ions by collisions with the molecules of the gas, is very nearly the same as the electromotive force required to produce spark-discharge in the gas at the same pressure and with the electrodes at the distance of $1 \mathrm{~cm}$.

Prof. Thomson illustrates this, in the paper mentioned above, by a small table taken from a paper by Skinner ( $\mathrm{Pbil}$. Mag. [5] 1. 1900). Here X (the potential-gradient per $\mathrm{cm}$. in the positive column) means the above described minimum E.M.F., and $p$ is the pressure. The table is as follows:-

\begin{tabular}{|c|c|c|}
\hline$p$. & $\mathrm{X} / \mathrm{cm}$. in Volts. & $\frac{\mathrm{X}}{p}$ \\
\hline $\mathrm{mm}$. & 27 & 45 \\
0.6 & 40 & 40 \\
1.5 & 56 & 38 \\
\hline
\end{tabular}

Liebig (Phil. Mag. [5] xxiv. p. 106) found the value required for a spark-discharge at a distance of $1 \mathrm{~cm}$. in air

* H. Geitel, Phys. Zeitschrifi, ii. p. 116 (1900) ; J. Elster \& H. Geitel, ibid. p. $560(1901)$.

t C. T. R. Wilson, Proc. Roy, Soe lxviii, p. 151 (1901).

$\ddagger$.I. J. Thomson, Phil. Mag. [5] 1. p. 278 (1900); ibid. [6] i. p. 361 (1901).

$\S$ J.S. Townsend, 'Nature,' August 1900 ; Phil. Mag. February and June, 1901. 
Dr. S. Guggenheimer on the Spark-discharge.

at atmospheric pressure to be 31,000 volts. This gives $\frac{\mathrm{X}}{p}=40 \cdot 8$. The fact that the values of $\frac{\mathrm{X}}{p}$ are nearly coincident seems to entitle one to draw the above conclusion. I hoped to be able to calculate the values of $\frac{\mathrm{X}}{p}$ for a wider range of pressures from the recent observations of Orgler*, but I was prevented from so doing as his numbers and curves do not apply for greater distances of the electrodes than $(1.5$ and $0.6 \mathrm{~cm}$. respectively. Paschent, also, in his well-known paper, does not give enough observations for a spark-length of $1 \mathrm{~cm}$. at different pressures to enable me to calculate the values of $\frac{\mathrm{X}}{p}$ in a sufficient number of cases.

Starting from the fact already mentioned, that even air at atmospheric pressure always contains ions, and that ions are continuously produced, it seems possible to obtain a fairly clear idea of what happens before a spark passes, as well as what happens during the spark-discharge.

If, for instance, one subjects two electrodes to slowly increasing electromotive forces, there will be formed immediately a very feeble current, as observed by Warburg and other experimenters. This current will, so long as no external agents are acting, remain constant within very wide ranges of the E.M.F.; but its intensity will increase very quickly and tend to a maximum, as soon as the E.M.F. attains the value necessary to give to the ions the velocity required to produce new ions by impact.

It seems to me that the experiments of Kreusler $\ddagger$ prove this very decidedly. It ought to be observed that in all his experiments (the final ones) the electrodes were exposed to ultra-violet light, but nevertheless when he approacbed the discharge-potential, a change in the value of the E.M.F. of $1.7,1.7$, and 1.3 per cent. (he used $\mathrm{Pt}, \mathrm{Cu}$, and $\mathrm{F} \theta$ electrodes) corresponded to an increase in the intensity of the current of $337 \cdot 2,243 \cdot 1$, and 392 per cent. The theory strongly demands that just as the spark-potentials are approximately the same, so also these last numbers ought to be the same; but it seems that here secondary circumstances of the experiments exert a certain influence.

Let us assume, for instance, the intensity of such a saturation current between the two electrodes to be only $\frac{1}{100}$

* A. Orgler, Ann. d. Physik, i. p. 159 (1900).

+ F. Paschen, Wied. Ann. xxxvii. p. 69 (1889).

f H. Kreusler, Ver. Phys. Ges. Bertin, 1898, p. 86, especially table, p. 91 . 
316 Dr. S. Guggenbeimer on the Spark-discharge.

of the intensity of the maximum current observed by Mr. Kreusler; thus let I (intensity) be $10^{-10}$ ampere. Then a simple calculation by means of the formula

gives

$$
\mathrm{I}=q e
$$

$$
q=2 \times 10^{9} \text { approximately, }
$$

where $q$ equals the number of ions per unit-volume. Comparing this value with Loschmidt's number, we see that only about the $10^{-11}$ part of the molecules become ionized. If no external ionizing agents are acting, then the transformation of the 20 ions contained in unit volume according to C. T. R. Wilson (if $I$ is greater then, of course, there is a correspondingly greater number of ions) into about $2.10^{\circ}$ ions must take plice by collisions. The time which is necessary for this transformation is what Prof. Warburg calls the period of retardation. It is obvious that this time is considerably shortened if we produce by radiation a new set of ions whose number is large compared with the number of ions originally present, which new ions are also put in motion, thus producing still more new ions by collisions with the molecules of the gas.

It will be easily seen that the above considerations explain fairly well Prof. Jaumann's results.

The following is a new definition of Maxwell's " electric strength" of a gas based on this view of the nature of the spark-discharge:- "The electric strength of a gas at a pressure $\mathrm{p}$ is defined as the electric intensity required to give to the negative ions a velocity sufficient to enable them to produce other ions by collisions wath the molecules of the gas." According to this view, the determinations of the sparkpotential under the action of radiation made by Prof. Warburg and his pupils are to be regarded as giving the normal sparkpotential, as Prof. Warburg maintains. It follows also that when working without radiation one ought to obtain the same normal potential, provided sufficient time is allowed for the electric intensity to act.

I hope soon to be able to publish further experimental results in support of these views.

The spark itself appears to amount practically to a short circuit between the electrodes. In addition to the production of ions by collisions, the following causes help to explain this :-

1. The ionization resulting from the high temperature of the spark.

2. The presence of hot metal vapour. 
3. The emission of cathode rays by the cathode due to the influence of the ultra-violet light given out by the spark.

In conclusion I wish to say that my heartiest thanks are due to Prof. J. J. Thomson for the kind and liberal bospitality " ith which he received me at his laboratory, and for the continuous interest he has taken in my work.

Cavendish Laboratory, Cambridge.

XXIX. The Anomalous Dispersion of Cyanin. By Privatdocent Dr. A. Prư̈ger, University of Bonn, Germany*.

IN several papers Wood $\dagger$ has communicated a new method of making prisms of solid cyanin, and also a repetition of the measurements of the dispersion-curve, as I made and used them severai years ago for the proof of the Ketteler-Helmholtz dispersion-formula $\ddagger$.

Using my photographic method, Wood finds that cyanin has a strong absorption-band in the ultra-violet, beginning at the wave-length $\lambda=372 \mu \mu$. He says that in this part of the spectrum it makes the measurements of the refractive indices impossible, since the strong absorption prevents any impression on the photographic plate, even with a five-hours' exposure. He continues $\$$ : "Pflüger found no traces of this band, and gives values for the refractive index within its limits. It seemed at first that the reason of this might be found in the difference in the optical properties of fused cyanin and that obtained by the evaporation of an alcoholic solution, but we have found that films prepared in the same way as those by Pflüger show the band also."

My ineasurements of the refractive index [after the manner accurately explained $\|]$ in this part of the spectrum were made on photographs, some taken with an exposure of 25 minutes, others with 40 minutes. The plates show plainly the double image of the iron lines used for the purpose of the measurements.

Furthermore, I have made photographs of the whole absorption-spectrum, which show plainly the absorption-band in the visible part of the spectrum, but not the faintest trace of an absorption in the ultra-violet. In these experiments the light of. an iron spark passed through a quartz plate

* Communicated by the Author.

† Wood and Magnusson, Phil. Mag. [5] xlvi. pp. 380-386; [6] i. pp. 36-45, January 1001. Wood, Phil. Mag. June 1901, pp. 624-627.

$\ddagger$ Pfliger, Wied. Ann. lvi. pp. 412-432; lxv. pp. 173-228.

$\S$ Phil. Mag. Jan. 1901, p. 41.

|l Wied. Ann. lxv. p. 199. 